\title{
WORK LIFE BALANCE AMONG WOMEN EMPLOYEES- A STUDY ON INITIATIVES UNDERTAKEN BY INDIAN ORGANIZATIONS
}

\author{
Sonia Delrose Noronha ${ }^{1} \&$ Dr. P. S. Aithal ${ }^{2}$ \\ 1, Research Scholar, Department of Management, Srinivas University, \\ Pandeshwar -575001, Karnataka, India. \\ ${ }^{1,2}$ Srinivas Institute of Management Studies, Pandeshwar, Mangaluru -575 001, India \\ E-Mail: soniadelrose@gmail.com
}

July 2019

\begin{abstract}
:
With the expansion in awareness and education identifying women empowerment there is a significant increase in the total number of working women in various areas. Ever changing market condition and competition has pressurized the enterprises to perish or perform. This has created tremendous pressure on the employees. Individual and professional life are the two aspects thought about significantly by representatives, the achievement of which requires real consideration. The real test for women is to balance and adjust the requests or the demands and the necessities of family and career. Different viewpoints like Work stress, socio demographic conditions, work pressure, effect of work on family life adversely influences the individual life and professional success making a discriminatory constraint for women which can be termed as Glass ceiling. Lack of appropriate work-life balance approaches practices and policies results in work-life strife. This can result in increased Labour turnover, high absenteeism, poor job satisfaction, continuous Organizational loss, and occupation fulfillment. There are initiatives and steps taken by the organizations and the administration. However the point be noted is if these steps taken are sufficient and are really profiting the employees. This paper based on the secondary data studies the work-life balance practices adopted by Indian organizations in providing Work life Balance among its Women Employees. An endeavor is likewise made to discover the difficulties experienced by the institutions in giving such measures to the women employees. The sources studied for this research includes different Internet sites, Journals, websites doctoral proposition, papers etc.
\end{abstract}

Keywords: Work Life Balance, Empowerment, Initiatives, Glass ceiling, Socio-demographic conditions.

\section{Introduction:}

Ever changing globalized focused business world has turned work-life balance into a matter of worry for employees, organizations as well as researchers. Organizations should know about the changing prerequisites and needs of the women employees at work and at home. Women employees are facing different issues and difficulties due to expanded obligations at work and individual life. To add on to it is conventions and partiality creating an unseen barrier in the career growth called as Glass ceiling. This prevents women employees from progressing in their occupation. This broadened way of life and changing work requirements have forced businesses to think on work life balance. Businesses currently give consideration towards work life and individual life. It has become a troublesome matter for women employees to maintain harmony or balance between personal life and professional work life. Work-life unevenness unfavorably 
influences the organizations, their close families, organizations and also the general public to such extent [13]. Suitable coping up practices ought to be provided to deal with the work and family requirements. This will boost the morale of the workers, increased job fulfillment, responsibility and productivity of the employees. In addition, it will also help in decreasing the labour turnover and absenteeism to some extent. In India, the scholarly endeavor to give a total picture of worklife balance practices and programmes adopted by different enterprises is very minimal.

\section{Objectives:}

1. To study the Initiatives available in maintaining Work Life Balance.

2. To identify the Current practices adopted by Indian organizations in Maintaining Work Life balance among its Women Employees.

3. To develop a Model showing the Benefits of Work Life Balance Initiatives on Individual, Family and Organization.

4. To Identify the Obstacles and Opportunities in this regard.

\section{Meaning and significance:}

Work life balance is an attempt towards limiting the job struggle of an individual employee by keeping up her discernments about job and his own time and family welfare. Work life balance can be characterized as employees' perception to keep up and incorporate numerous areas of work, individual and family care with least job struggle [5]. Patriarchy system in the society kept women from performing and appreciating crucial jobs in the society. Inclusive Development points towards investigating women to their fullest potential and add to the financial development and flourishing of the nation by tending to their differential needs. Issues looked by women are disregarded in the male commanded social orders, which looks for prompt consideration of the Government, associations, social administration organizations and worker's organizations. Nature of work life balance is the cutting edge pattern to enhance confidence of the representatives and profitability of the associations [14]. Work life balance can be different to various individuals depending on the diverse phases of life. It essentially incorporates the issues of depletion and absence of time. Research demonstrates that inability to accomplish a satisfactory equalization of effort is directly associated with absence of vitality to satisfy individual responsibilities and absence of authority over the outstanding task at hand. The lopsidedness here prompts results, for example, fatigue, low quality of life and in particular low performance. Work life balance is the connection between work and home duties and its effect on each other. The present examination inspects the current work-life balance approaches and practices adopted by different Indian organizations. With the increase in the women workforce, nuclear and dual earner families the requirement for the employees to adjust their work and individual life has likewise expanded. Besides, women still assume the significant responsibility of spouse care, childcare, elderly care and house work, extended work hours, work culture and absence of adaptable work arrangement makes a disadvantageous circumstance for women employees than men. Women seem to find it difficult to put in the required number of hours to propel in their occupation. Considering this prerequisite alongside the goal to give better personal satisfaction and maintenance of effective skilled representatives, organizations are presently giving different work-life programs. Organizations are showing concern towards their employees by planning welfare approaches like positive working environment, increasing well-being, and safety. Post-war time has shown increase of statutory and government-arrangements offered to employees, for example, medical coverage, standardized savings estimates like pension and protection and compensation plan in 
case of disease and accidents showing the obligation of originations towards employees in order to provide social security to employees and their families [8]. In the present paper, an attempt has been made to recognize and uncover the present status and advantages of work-life balance programs given by different Indian Organizations and its future difficulties. This investigation depends on the information got from literature survey. As women still do most of childcare and residential work, an absence of flexible working arrangement and an extended work hours will disservice a larger number of women than men, as they will be unfit to put in required hours to build their career.

\section{Methodology}

This research is descriptive in nature. The analyst has gathered secondary data from journal papers, published papers, articles, newspapers etc.

\section{Current initiatives in work life balance}

Organizations have begun executing many work-life balance practices. They offer dependent elder care, children care, flexi-work schedules, and work sharing and employee help programs as choices for maintaining work life balance [6]. These measures help the business to hold high potential key employees and productive workforce. Present modern organizations have begun to adopt such trends [10].

- Paternity Leave: Central Civil Services, Leave Rules 43-A provides Paternity leave to male government workers' up to a time of 15 days amid childbirth [4]

- Maternity Leave: Rise in the number of women employees and the problems identified with work-life balance different approaches like Maternity Benefit Act 1961 which gave 12 weeks(three months) paid leave to all ladies representatives has been changed in 2016 and expanded to 26 weeks i.e. six months[ 12]

- Parental leave: Parental leave is benefited by parents to care for a young child and to make plans for the child's welfare. Guardians can likewise utilize this leave to invest more time with their children and strike a harmony among work and individual family duties.

- Family leave: This arrangement benefits the employees to avail leave facility to cater to the illness of the family (parents, spouse or children) on the arrangement of the medical certificate. Every worker here has a privilege to take family leave which cannot be deferred or cancelled.

- Unpaid leave: If a worker wishes to take a break from their work to offer importance to other professional or individual needs, organizations may consider through unpaid leave.

- Teleworking: This is a work plan where a worker might be approved to do some portion of their exercises regularly from home over some stretch of time. Employee may request the employer for teleworking however this does not give a right to a worker to telework automatically.

- Part time work: Employees who want to work on part time basis due to different reasons, such as pursuing higher education, attending family requirements, contemplating hobbies and numerous others can offer significance to needs other than work. Part time employees may benefit by this approach.

- Flexi-time Concept: This is an arrangement that enables a worker to make his own planning for beginning and completing work with the scope of accessible hours subject to accomplishing absolute day by day, week after week or month to month hours. It is a gainful open door given 
by organizations to its employees of adaptable hours with a condition of the employees' availability in the organization during the core working hours.

- Time to care for sick children: Taking some time off to take care of the children or to get the child who is sick from crèche or school is a provision that can help employees to keep up work life balance.

- Crèches': Certain organizations arrange their very own crèche where the workers can leave their young children. This will end the predicament that compels women employees to pick among children and work.

\section{Model showing initiatives and its benefits towards work life balance}

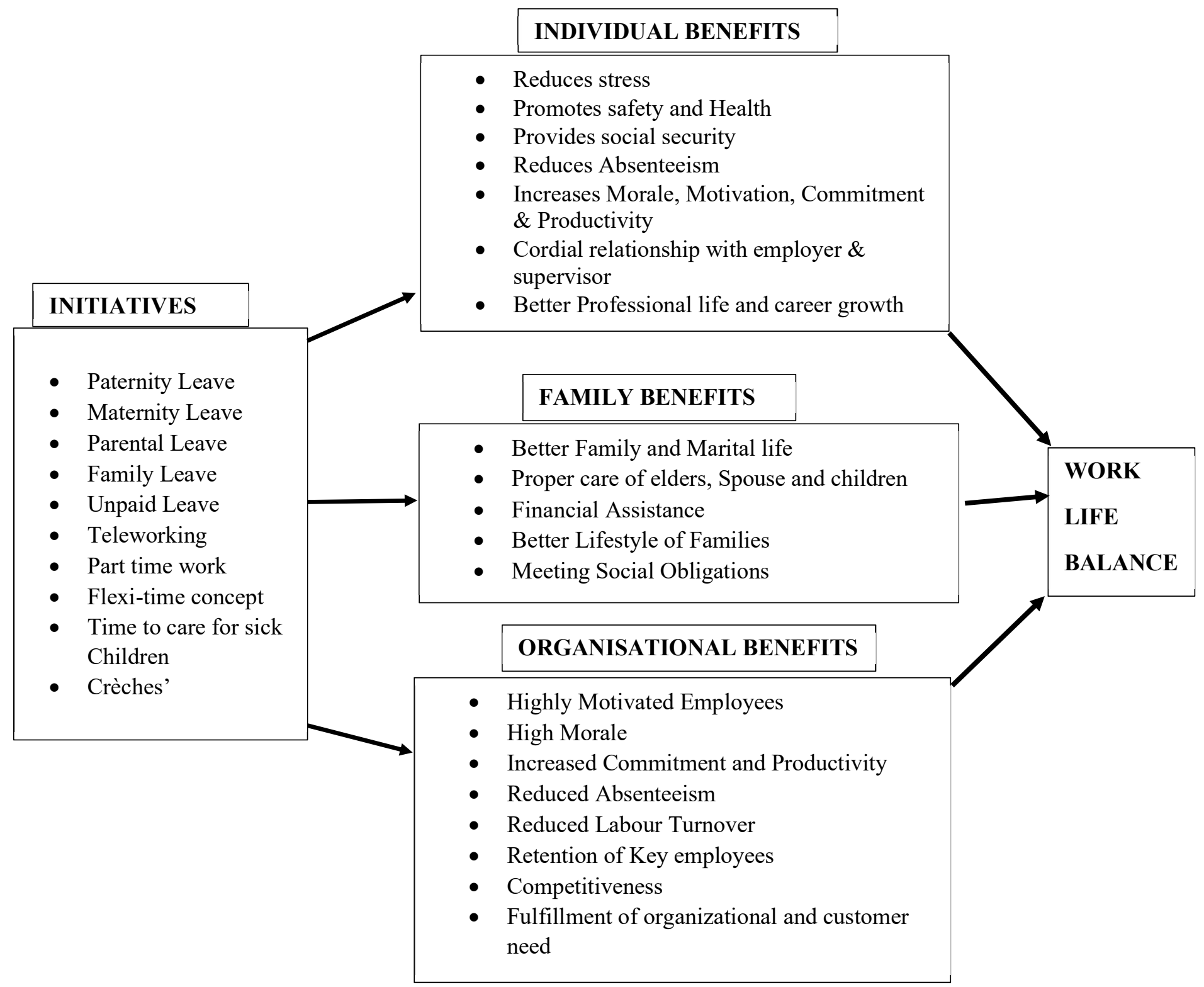


Figure 1. Model showing the benefits of Initiatives on Individual, Family and Organization.

Figure 1 shows the practices that can be adopted by the Organizations and the benefits of these Initiatives on the Individual, Family and Organization. If these initiatives are adopted considering the financial aspects, it will help in maintaining Work Life Balance among women employees thus helping the organization in achieving its objectives.

\section{Initiatives adopted by Indian Organizations}

Organizations are presently endeavoring extraordinary efforts to provide caring, positive and engaging work condition. An examination comprising of 20 Fortune 500 organizations has discovered that $28 \%$ of the men and $53 \%$ of the women revealed failure to concentrate at work because of work family pressure. This shows the greater part of women and $33 \%$ of men are influenced by work-family pressure. This is the consequence of the increase in the number of dual earners resulting in work-life strife [7]. In Mind Tree and Pepsi Company, worker engagement methodologies are excitedly helping them to keep up better work-life balance. At Marico Company, workers depending upon their jobs have the flexible options to choose the timings of their work after obtaining consent from the employer. The organization does not keep up any framework for estimating work hours or maintain attendance registers. Citi India has as of late presented an approach that permits employees to telecommute for two days in a month (depending on the role of employee). Employees have the opportunity to settle on remote working and flexitime concept. Attendant service has been as of late presented by the organization inside the workplace premises to assist representatives with freeing up important time. It is even known for its possibility for leave arrangement where the workers can look for oral leave permission from the manager. The record of such leave isn't kept up for a time of four days [11]. Pepsi Co India has begun an idea of solid, healthy and free breakfast with fruits, oats, natural products, Poha and Upma. This has helped the young, single and unmarried employees. Recently they have started for newly married employees. Pepsi Co has tied with Ida and Intelliots for giving day care offices in Gurgaon, Mumbai, Hyderabad, and Chandīgarh. Here workers can profit enormous discount of Rs.40, $000-50,000$ alongside different advantages. Dabur India is focusing on the wellbeing and wellness of workers understanding that a sound representative is a profitable representative. CocaCola urges employees to try out healthy living techniques like tennis, Aerobics, Gyms Yoga by financing up to half of the costs caused on memberships. Mahindra and Mahindra urges workers to go for regular medical checkups by having tie-ups with diagnostic places and Stepathlon Lifestyle. Raychem RPG offers 101 facilities like maintenance of gadgets, elder care, pet care, getting laundry done due to which employees to make the most of their extra time and enjoy weekends. Infosys Technologies' gives wellness activity Health Assessment Lifestyle Enrichment (HALE). In order to reduce stress Wipro likewise offers wellness health initiative. Johnson and Johnson India in 2002 began Women's Leadership Initiative (WLI) to bring in women leaders in the organization. The organization additionally made mindfulness on medical problems by creating health awareness issues, supporting tribal girls, supporting street children, helping orphans and providing gynecological and maternity care to women. On order to increase employee productivity Procter and Gamble India has reduced work routines and has offered representatives to telecommute helping employees to maintain work-life balance [1]. Intel India gives workplace solutions to decrease work and individual difficulties and personal challenges increasing the work value of Intel. Along with adaptable flexible working hours, only five days' work in a week is also adopted. It likewise gives Hospitalization Insurance Policy along with reimbursement of expenses incurred at the hospital by the employee and his dependents who are insured under a floater policy 
(Rs.500,000 p.a) Intel additionally pays the premium of employees and their dependents. Employees $100 \%$ premium and dependents $80 \%$ premium is pain by Intel. Spouse and employees also get maternity insurance cover under Hospitalization Insurance. Intel Gives every employee paid maternity leave of 84 days in the case of pregnancy. On long periods of service 15 days for initial two years and 20 days for over two years) annual leave facility are offered to employees apart from 12 public holidays in a given year. Intel under Business Traveler Medical plan, gives medical coverage to its workers when they are on business travels outside India (for a period of 90 days).This facility is offered to both full time and part time employees. In case of the death of insured employee Intel guarantees payment of lump sum amount to the legal heir of the deceased employee. Intel pays $100 \%$ premium. Other benefits offered by Intel are compressed work week, flexible work hours, telecommunicating, alternate work schedules, part time employment, health benefits, child care assistance and also wellness benefits. IBM India gives to its employees choices like telecommuting, part time employment, flexible work week and family counselling. Arrangements include recreational activities, clubs, reimbursement, global chances, and career break and life events like marriage. This encourages IBM to attract the best talent motivate and retain them. TATA Group, being one of the most seasoned and respected group is known people centered organization. It is additionally known to have high scores on welfare parameters. Here work-life balance activities are custom fitted according to various strata of representatives. For the workforce in manufacturing and assembling plant, organization has presented adult education programme and also family life education. Crèche office is given to support the female employees. IBM's approach says that association is particular about providing employees an opportunity to accomplish work life balance. TATA Consultancy Services (TCS) a developing Organization started under Tata group has a pool of qualified executive class employees. The organization gives to its worker's choices to work flexi time with certain compulsory work hours and arrangements to work for five days in a week. Most noticeably TCS organizes regular seminars on better living, stress management and nutrition. Realizing and understanding the effect of desk bound jobs, extensive travel and long working hours that result in work-life imbalance the organization has empowered the development of groups with comparative same interests to meet up and organize various activities other than routine work. Child care and crèche facility is provided by Zensar Technologies. Casual gathering is encouraged where employees can meet their seniors to discuss anything. Day to day activities like dropping cheques, drawing cash, paying bills, school fees of employees children is offered by Zensar through a facility called Madat online a 24/7 facility. Zensar Technologies conducts stress management programmes, fun days at work and also family day. This shows Indian Organizations have now understood the requirement for work-life balance and are taking necessary steps to help employees have work-family amicable condition and work life balance [2].

\section{Obstacles and Opportunities}

Despite the fact that Indian Organizations are attempting their best to give work life balance programs, numerous associations think about it as a burden and not a strategic choice. In the current circumstance where the organizations are going worldwide decreasing expense or cost cutting is the greatest challenge for Organizations. Strategy formulators feel that work-life balance activities will result in financial burden. This increase in the budget will make it challenging for them to survive in this aggressive worldwide market. Human Resource Department needs to productively use human assets by investigating some inventive approaches and practices. The McCrindle's Research of 3000 Australians shows that work-life balance is the important factor for attracting 
and retaining efficient employees. This can be ranked above the salary component. Numerous analysts have demonstrated that work and family are not separate but rather impact each other [9]. In India where an ever increasing number of women are getting into workforce statutory approaches, for example, maternity benefit with leave is common but concepts like work from home, flexi time, part time are sporadic and are optional in nature. Additionally, approaches and practices like paternity leave, working from home, well-being help programs, child care, elder care leave, and stress management programmes are yet to be considered as a strategic decision and a vital choice by the organizations. Indian organizations consists of the youthful, enthusiastic and proficient workforce. But the point to be stressed is the steady increase in the attrition rate in organized sector in India was $26.9 \%$ in 2013, most astounding attrition rate worldwide [3]. Worklife balance techniques motivate and increase the employee's performance thus resulting in increased morale. Work-life balance gives employees opportunity to utilize their spare time effectively and satisfy different activities and commitments along with organizational work. All the more significantly, it diminishes employee's psychological pressure and results in job fulfillment. In this way the organizations ought to understand the esteem requirements of work life balance initiatives on employees as well as organizational performance.

\section{Conclusion}

For today's organizations the buzz word to success is work-Life Balance for women employees. Different strategies are formulated and executed by the organization. Women are likewise expected to identify coping strategies to adjust to the family and work demands. These lifestyle practices will support the employees and the employers to manage the issues and the problems of work life balance. The work-life balance creates harmony and peace in the lives of the employees. It is a survival technique for the business in the extreme focused market as it increases the value of the work culture and furthermore family life. Institutions have understood the intensity of worklife balance techniques and are attempting their best to execute it effectively. This awareness will assist associations with retaining and utilize the talents and abilities of the employees to the greatest extent.

\section{References}

1. Andukuri Raj Shravanthi, Sagar Deshmukh, N. Deepa (2013), "Work Life Balance of Women in India", International Journal of Research in Management Sciences, 1(1) 50.

2. Barik, P., \& Pandey, B. (2016), "Work Life Balance a Strategic Human Resource Policies and Practices followed by Indian Organisations", IRA- International Journal of Management \& Social Sciences, 5(3). 427-435.X

3. Biswas S. (2013), "Attrition In India to top world charts in 2013; one in four employees to change jobs", www.economicstimes.indiatimes.com/jobs/attrition-in-India-t-top-worldcharts-in-2013, The economic times, June 07, 2013

4. Central Civil Services, Paternity Leave, CCS (Leave) Rules 43-A, Central Government staff news posted on Sunday, November 25,2012

5. Clark SC, (2000), "Work /Family Border Theory: A new Theory of Work / Family Balance. Human Relations", 53(6): 747-770

6. Dalcos, S.M., \& Daley, D.(2009), "Work Pressure, Workplace social resources and work -family conflict: The tale of two sectors", International Journal of stress Management, 16(4), 291-311. 
7. Francene Sussner Rodgers, (1992), "When the Business Case in common sense: Coming to terms with America's Family Challenge", autumn 1992, ACA Journal.

8. Glass, J.L., \& Estes, S.B. (1997), "The Family responsive workplace. Annual Review of Sociology", 23(1), 289-313

9. Greenhaus, J.H and Powell, G.N (2006), "The Academy of Management Review", 31(1), $72-92$.

10. Hobsor, C.J., Delunas, L., \& Kelsic, D. (2001), “Compelling evidence for the Need for Corporate work/Life Balance initiatives: Results from a national survey of stress fill lifeevents. Journal of employment counselling", 4(8), 38-44.

11. Manabí Pathak (2014), "Psychology at work, making Managers responsible". www.humancapitalonline.com.

12. Maternity Benefit(Amendment) Act, 2017, Ministry of law and Justice, New Delhi, 28 March ,2017

13. Noronha, S., \& Aithal, P.S. (2016), "Glass Ceiling - A Silent Barrier for women in Highly Advanced and Humanistic Society”. IRA-International Journal of Management \& Social Sciences, 5(3), 455-466

14. Sonia Delrose Noronha, P.S. Aithal \& M. D. Pradeep, "Study on Policy Framework towards Work Life Balance in India ", International Journal of Multidisciplinary Research and Modern Education, Volume 3, Issue 2, Page Number 11-16, 2017. 